\title{
Mechanism of the anthracene-transfer in a topochemically controlled regiospecific antipodal $\mathrm{C}_{60}$ difunctionalization
}

Radu A. Talmazan, ${ }^{1}$ Klaus R. Liedl,,${ }^{1}$ Bernhard Kräutler, ${ }^{2}$ Maren Podewitz*1

${ }^{1}$ Institute of General, Inorganic and Theoretical Chemistry, and Centre of Molecular Biosciences, University of Innsbruck, Innrain 80/82, 6020 Innsbruck, Austria

${ }^{2}$ Institute of Organic Chemistry, and Centre of Molecular Biosciences, University of Innsbruck, Innrain 80/82, 6020 Innsbruck, Austria 


\section{ABSTRACT}

Ever since the discovery of fullerenes, their mono- and multi-functionalization by exohedral addition chemistry has been a fundamental topic. A few years ago, a topochemically controlled regiospecific di-functionalization of $\mathrm{C}_{60}$ fullerene by anthracene in the solid state was discovered. In the present work, we analyze the mechanism of this unique reaction, where an anthracene molecule is transferred from one $\mathrm{C}_{60}$ mono-adduct to another one under exclusive formation of equal amounts of $\mathrm{C}_{60}$ and of the difficult to make, highly useful, antipodal $\mathrm{C}_{60}$ bis-adduct. Our herein disclosed dispersion corrected DFT studies show the anthracene transfer to take place in a synchronous retro Diels-Alder/Diels-Alder reaction: an anthracene molecule dissociates only partially from one fullerene when already undergoing bonding interactions with a neighboring fullerene molecule, facilitating the reaction kinetically. Hence, the anthracene transfer occurs via a stabilized intermediate, in which a planar anthracene molecule is sandwiched between two neighboring fullerenes and forms equally strong "double-decker" type $\pi$ - $\pi$ stacking interactions with both of these fullerenes. Analysis with the distortion interaction model shows that the anthracene unit of the intermediate is almost planar with minimal distortion. This analysis sheds light on the existence of simultaneous noncovalent interactions engaging both of the two faces of a planar polyunsaturated ring and two convex fullerene surfaces in an unprecedented 'inverted sandwich' structure. 


\section{INTRODUCTION}

Fullerenes, the spherical molecular carbon allotropes first discovered in mass-spectrometric experiments in $1985,{ }^{1,2}$ and soon thereafter available in crystalline preparative form, ${ }^{3}$ open up exciting fields of chemical research. ${ }^{4-7}$ The unique properties of the icosahedral $\mathrm{C}_{60}$ molecules have particularly inspired a multitude of studies concerning the functionalization of this polyunsaturated carbon compound by the means of addition reactions. ${ }^{2,5,8}$ Early on, a range of cyclopropanations ${ }^{4,8,9}$ and pyrrolidine forming reactions ${ }^{8,10}$ were used very effectively, as were other formal cycloaddition reactions. ${ }^{8}$ The synthetic interest in the chemistry of $\mathrm{C}_{60}$ was further boosted by its pronounced and theoretically rationalized selectivity for cycloaddition reactions at its so called [6,6]-bonds. ${ }^{6,8,11-13}$ Indeed, the thermally reversible [4+2]-cycloaddition (Diels-Alder, DA) reaction has become a most versatile methodology for the creation of exohedrally functionalized fullerene derivatives, ${ }^{8}{ }^{14-17}$ opening up entries to a vast array of covalent fullerene derivatives. ${ }^{8}$ The spherical architecture of the fullerenes induces pyramidalization of the unsaturated carbon centers, ${ }^{18}$ rendering the polyunsaturated $\mathrm{C}_{60}$ electrophilic and specifically dienophilic and making $\mathrm{C}_{60}$ a prototype candidate for [4+2] cycloaddition reactions. ${ }^{8}, 16$ Polycyclic aromatic hydrocarbons were found to represent surprisingly suitable diene-components for functionalization of $\mathrm{C}_{60}$ by [4+2] cycloaddition reactions, such as anthracene, ${ }^{8,17,19-22}$ other acenes, ${ }^{23-26}$ and derivatives thereof. ${ }^{27}$ The experimental work on fullerene functionalization by $[4+2]$-cycloaddition has been accompanied and guided by insightful theoretical studies. ${ }^{28-31}$ Suitably functionalized fullerenes have found a wide range of applications as key components, ${ }^{32-}$ ${ }^{35}$ in photovoltaic devices, ${ }^{36-40}$ in artificial photosynthesis, ${ }^{41,}{ }^{42}$ drug delivery, ${ }^{33,}{ }^{43}$ bio- and nanomedicine, ${ }^{42,43}$ in material science, ${ }^{32,44-49}$ and in self-healing polymers. ${ }^{50,51}$

The molecular features of the fullerenes as polyunsaturated spherical carbon compounds have attracted particular attention to the question and the opportunities of the synthesis of di- and multifunctionalized derivatives with high regio- and stereo-control. ${ }^{8,52-58}$ The unique symmetrical structure of $\mathrm{C}_{60}$ was recognized as a remarkable spherical carbon unit for sequential addition reactions and the creation of multi-adducts with exceptional architectures. ${ }^{58-64}$ The inherent propensity for multiple [4+2]-cycloaddition reactions has also been observed in the reactions between the fullerene $\mathrm{C}_{60}$ and anthracenes, where not only mono-adducts were prepared, ${ }^{16,17,19,22 \text {, }}$ ${ }^{27,65}$ but bis-adducts ${ }^{20,65-69}$ and specific tris-adducts, as well. ${ }^{64,70}$ The kinetic and thermodynamic 
driving forces for the formation of specific bis- and tris-adducts has become a much discussed issue. ${ }^{8}$ Thermolysis of crystalline mono-adduct of $\mathrm{C}_{60}$ and anthracene has provided a strikingly efficient means for achieving regio-specific antipodal bis-addition. ${ }^{66}$ The exquisite selectivity in this process was proposed to result from topochemical control in the solid state, ${ }^{21,66}$ because the alternative solution chemistry led to a mixture of anthracene adducts, among them the antipodal bis-adduct as only a minor component. ${ }^{20,71}$

The (thermal) DA reaction has become a fundamental synthetic method for the stereo-controlled formation of two new C-C bonds in a 6-memberd ring structure, and a mechanistic textbook topic of (orbital and state) symmetry control, ${ }^{72-75}$ thoroughly investigated in critical classical experimental and theoretical studies. ${ }^{76-79}$ For typical hydrocarbons the two new C-C bonds formed by the DA reaction are made in a concerted and thermally reversible process. ${ }^{80-85}$ Quantum chemical studies have fully verified these 'basic rules' of the thermal [4+2]-cycloaddition chemistry. ${ }^{86-91}$ However, the spherical structure of the $\mathrm{C}_{60}$ molecules results in a pyramidalization of their unsaturated carbon centres, an early recognized relevant factor for further enhancing reactivity in exohedral addition reactions. ${ }^{8}, 92$ The pyramidal nature of the unsaturated carbon centers of $\mathrm{C}_{60}$ pre-activates them for bonding interactions with unsaturated reaction partners at their convex exo-face, ${ }^{29,93}$ decreasing the activation barrier in DA reactions. ${ }^{94}$ On the way to their cycloaddition products, aromatic hydrocarbon first associate with $\mathrm{C}_{60}$ to a non-covalently bound intermediate complex. ${ }^{52,74}$ This activates towards reaching the transition state on the way to the new C-C bonds. As pointed out by Osuna, ${ }^{29}$ non-covalent interactions govern the stability of fullerenes and aromatic hydrocarbon intermediates, and an adequate description of these interactions in computational investigations has to be accounted for. ${ }^{52,83}$ Recent studies with the example of benzene and $\mathrm{C}_{60}$ shed light on the interaction of a planar aromatic compound and a curved fullerene surface, ${ }^{74}$ which was shown to be different in nature from $\pi-\pi$ stacking interactions between two planes.

Regioselectivity of the DA cycloaddition with $\mathrm{C}_{60}$ has also been a point of computational investigations. ${ }^{58,67,95-98}$ The group of Bickelhaupt and Sola suggested the addition to the so called $[6,6]$-bond, to be preferred over the [5,6]-position, because of more favourable interactions between the reactants in the transition state,${ }^{87}$ as was confirmed by decomposition of the electron 
activity ${ }^{88}$ The former argument was also put forward by Garcia-Rodeja et al. to rationalize the regio-selectivity of bis-cycloaddition reactions to fullerenes. ${ }^{89}$

In the solid state, the regio-specific formation of the antipodal bis-adduct from the crystalline mono-adduct of $\mathrm{C}_{60}$ and anthracene was observed. ${ }^{66}$ This suggested a topochemically controlled anthracene transfer between two pre-aligned mono-adducts, possibly taking place in a synchronous fashion, as schematically shown in the lower panel B of Scheme $1 .{ }^{66}$ However, the detailed reaction mechanism of this anthracene transfer was not established. In a most basic formal mechanism this result would be achieved by a complete dissociation of the anthracene moiety from one monoadduct by a retro-DA reaction, followed by the highly regio-selective DA-cycloaddition at another one. Alternatively, the anthracene transfer could proceed via an unprecedented direct one-step reaction, where the transition state would represent a planar anthracene molecule interacting similarly with both fullerenes, or via a synchronous two-step reaction, where in a retro-DA step an intermediate is first formed that exhibits (non-)covalent interactions with both neighbouring fullerene moieties, followed by an addition at the back of mono-adduct to generate the antipodal bis-adduct. Unravelling this reaction mechanism is of significant interest, as it implies a correlated defunctionalisation of one mono-adduct molecule, coupled with functionalization of a neighbouring mono-adduct molecule. Hence, a thorough computational analysis of this anthracene transfer between two fullerenes was carried out, in order to gain insights into the simultaneous interaction of two spherical and one planar poly-unsaturated carbon molecules.

Due to the size of the system and the lack of a high-resolution crystal structure, this solid-state reaction was modelled in the gas phase. This approach is reasonable, since all reaction partners are neutral and thus, long-range electrostatic interactions are expected to be minimal. We chose to investigate the topochemically controlled regiospecific anthracene transfer by two model reactions: Reaction $\mathrm{A}$ describes the transfer of one anthracene molecule from one $\mathrm{C}_{60}$ fullerene mono-adduct to a $2^{\text {nd }} \mathrm{C}_{60}$ fullerene (Scheme 1, panel A), while reaction $\mathrm{B}$ describes the transfer of one anthracene from one $\mathrm{C}_{60}$ fullerene mono-adduct to another $\mathrm{C}_{60}$ fullerene-anthracene monoadduct, resulting in the creation of an antipodal bis-adduct (Scheme 1, panel B). Density Functional Theory (DFT) calculations were performed to elucidate the reaction mechanism, not only from a thermodynamic and kinetic point of view, but also in view of the non-covalent interactions present between the reaction partners in each species. 
A.
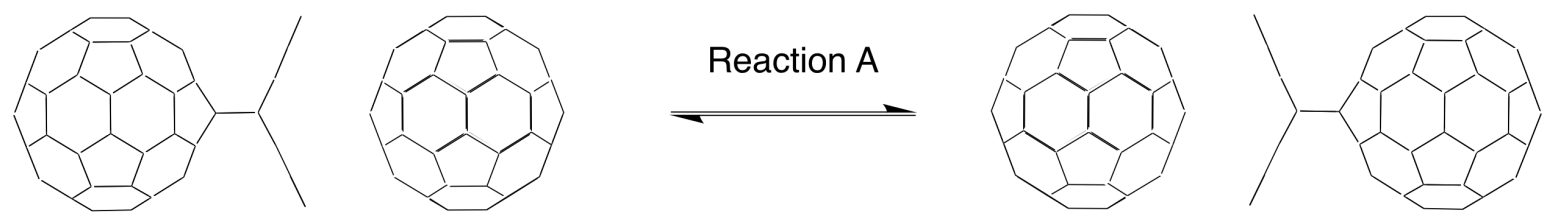

B.
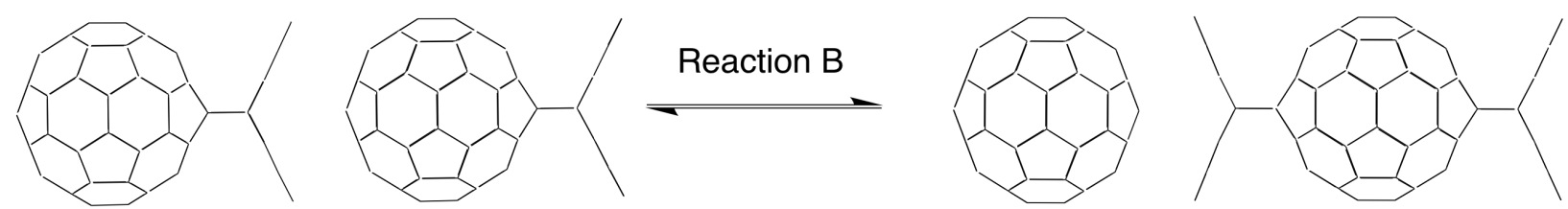

Scheme 1. Schematic Representation of investigated topochemically controlled anthracene transfer reactions. Reaction A depicts the transfer of one anthracene molecule from one $\mathrm{C}_{60}$ :anthracene mono-adduct to a $\mathrm{C}_{60}$ fullerene. Both the product and the educt represent identical structures. Reaction $\mathrm{B}$ depicts the anthracene transfer from one $\mathrm{C}_{60}$ :anthracene mono-adduct to another, resulting in the creation of one trans antipodal bis- adduct and one $\mathrm{C}_{60}$ fullerene.

\section{COMPUTATIONAL METHODOLOGY}

As no high resolution X-ray crystal structures were available, the initial structures for the $\mathrm{C}_{60}$ fullerenes and $\mathrm{C}_{60}$ :anthracene mono-adduct were set-up using Gaussview 4.1.2. ${ }^{99}$ All subsequent structure optimizations and harmonic frequency calculations were performed using Turbomole $7.3^{100}$ and were done in C1 symmetry. Structure optimizations have been carried out with Density Functional Theory (DFT) utilizing the GGA density functional BP86 $6^{101-104}$ in combination with the def2-SVP basis set. ${ }^{105}$ As shown in previous studies, empirical dispersion corrections, that are not intrinsically dealt with in DFT, are essential to obtain reliable structures in such extended $\pi$ systems and to localize reaction intermediates. ${ }^{106}$ Therefore, Grimme's empirical dispersion corrections with Becke-Johnson damping of the DFT-D3 ${ }^{107}$ type were employed in all calculations. Selected structures were re-optimized with BP86/def2-TZVP ${ }^{108} / \mathrm{D} 3$ but structural differences were found to be small. Reported electronic energies were calculated as single points BP86/def2TZVP/D3 on the BP86/def2-SVP/D3 optimized structures. An even larger def2-QZVP ${ }^{109}$ basis set yielded very similar single point energies with differences less than $2 \mathrm{~kJ} \mathrm{~mol}^{-1}$ compared to def2TZVP. Hence, the triple-zeta def2-TZVP basis set was considered accurate enough. To test the 
effect of the density functional, single point calculations with B3LYP ${ }^{101,104,110,111 / \text { def2-TZVP/D3 }}$ were computed on the BP86/def2-SVP/D3 optimized structures too. To validate our chosen methodology (density functional/basis set), we compared both structural parameters with known experimental data. As to our knowledge, currently no crystal structure of the $\mathrm{C}_{60}$ : anthracene mono-adduct exists, we compare our calculated structures to the available experimental $\mathrm{C}_{60}$ :antracene bis-adducts ("edge" and "trans-4") structures. ${ }^{68}$ Through the comparison with the trans-3 and edge $\mathrm{C}_{60}$ :anthracene bis-adducts, it is shown that the methods chosen offer accurate structures, as the bond lengths deviate less than $0.01 \AA$ from their crystal counterparts, while the angles and dihedrals are within $0.1^{\circ}$. As the initial reaction is in solid-state, involving no charged species, no long-range interactions were expected, thus, modelling the reaction in gas phase is adequate.

The correct stationary points were identified through harmonic frequency calculations, by examining the eigenvalues of the hessian matrix corresponding to each structure. Minima show only positive eigenvalues, while a transition state show exactly one imaginary eigenvalue and its associated eigenvector corresponds to the reaction coordinate.

To obtain Gibbs free energies, zero-point energies and thermal corrections at $298.15 \mathrm{~K}$ were calculated via approximation of the partition function by the standard rigid rotator and harmonic oscillator model using Turbomole's freeh tool. Obtained harmonic frequencies were scaled with a factor of $0.9914^{112}$ to increase the accuracy. These corrections were calculated with BP86/def2SVP/D3 and added to the BP86/def2-TZVP/D3 electronic energies.

The 2D potential energy surfaces (PES) scans were obtained by modifying the structure along the chosen degrees of freedom in Pymol, ${ }^{113}$ then subsequently calculating single point energies of each resulting structure. The resulting PES is visualized with Origin $2018 \mathrm{~b} .^{114}$

To highlight the non-covalent interactions, NCI plot was used, ${ }^{115}$ where the second eigenvalue of the electron-density Hessian matrix, $\operatorname{sign}\left(\lambda_{2}\right) \rho$, is depicted on an isosurface of the reduced gradient $s .{ }^{116}$ Areas with (weak) non-covalent interactions are characterized with a low (reduced) electron density gradient and a $\operatorname{sign}\left(\lambda_{2}\right) \rho$ close to zero (depicted in green). Large negative values of $\operatorname{sign}\left(\lambda_{2}\right) \rho$ are indicative of attractive interactions (depicted in blue), whereas large positive values of $\operatorname{sign}\left(\lambda_{2}\right) \rho$ indicate non-bonding repulsive interactions (depicted in red). 
All structures were visualized using Pymol, ${ }^{113}$ except for those depicting non-covalent interactions, which were displayed with VMD. ${ }^{117}$

\section{RESULTS}

Mechanism of the topochemically controlled regiospecific $C_{60}$ fullerene-anthracene transfer reaction

Prior to investigating the $\mathrm{C}_{60}$ fullerene-anthracene transfer reaction, we evaluated the reaction energies associated with the formation of an isolated $\mathrm{C}_{60}$ :anthracene mono-adduct, see Scheme 2 (panel A), for which we found a stabilizing energy of $\Delta \mathrm{E}=-63.6 \mathrm{~kJ} \mathrm{~mol}^{-1}$ and $\Delta \mathrm{G}=7.4 \mathrm{~kJ} \mathrm{~mol}^{-1}$. The formation of the complex 1 from the constituents yields an even larger energy gain of $\Delta \mathrm{E}=$ $123.7 \mathrm{~kJ} \mathrm{~mol}^{-1}$ and $\Delta \mathrm{G}=3.2 \mathrm{~kJ} \mathrm{~mol}^{-1}$ (see panel B). Therefore the coordination of a $2^{\text {nd }} \mathrm{C}_{60}$ fullerene to the $\mathrm{C}_{60}$ :anthracene mono adduct to form 1 , exerts a stabilizing effect of $\Delta \mathrm{E}=-60.1 \mathrm{~kJ} \mathrm{~mol}^{-1}$ and a free reaction energy of $\Delta \mathrm{G}=-4.2 \mathrm{~kJ} \mathrm{~mol}^{-1}$ (panel C). Similarly, aligning two $\mathrm{C}_{60}$ :anthracene monoadducts, to form the complex 2 , also results in a stabilization of $\Delta \mathrm{E}=-58.5 \mathrm{~kJ} \mathrm{~mol}^{-1}$ and $\Delta \mathrm{G}=-7.8$ $\mathrm{kJ} \mathrm{mol}^{-1}$. It is noteworthy here that the stabilization energy of the second reaction partner to form the stable complexes $\mathbf{1}$ and $\mathbf{2}$, is roughly the same as the formation energy of the $\mathrm{C}_{60}$ :mono-adduct, $-60.1 /-58.5 \mathrm{~kJ} \mathrm{~mol}^{-1}$ vs. $-63.6 \mathrm{~kJ} \mathrm{~mol}^{-1}$. 
A.

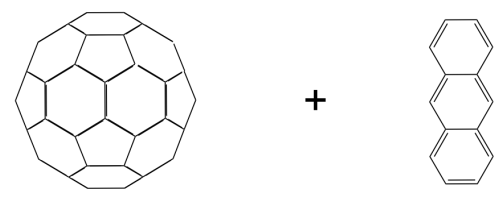

B.

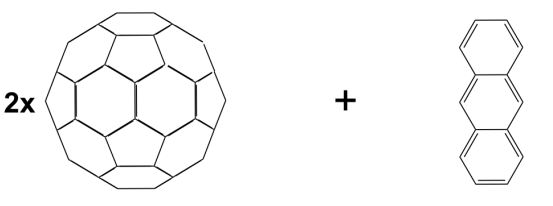

C.

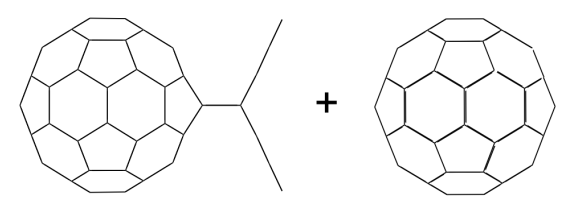

D.

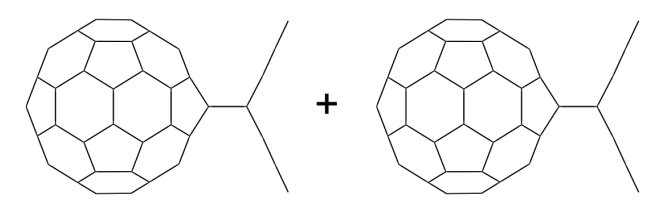

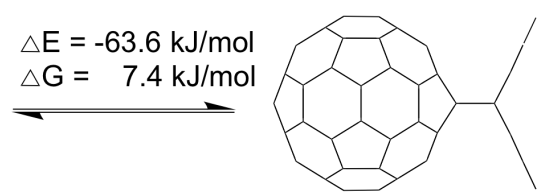

$\mathrm{C}_{60}$ :anthracene mono-adduct
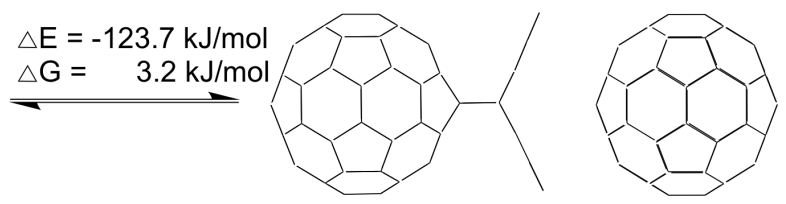

1
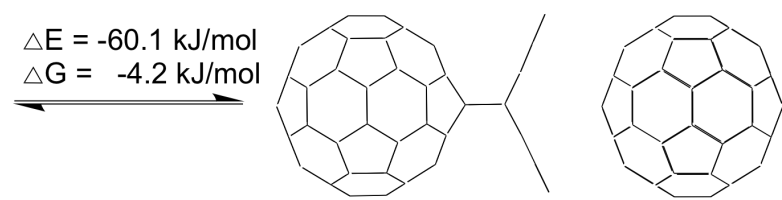

1
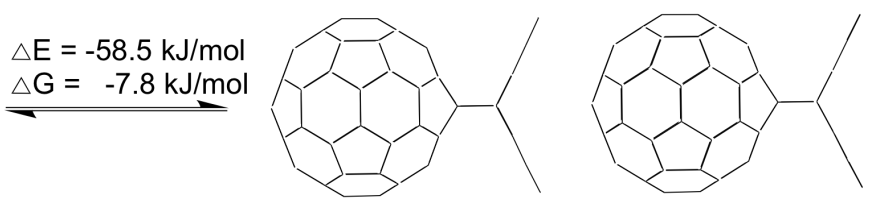

2

Scheme 2. Formation of the isolated $\mathrm{C}_{60}$ :anthracene mono-adduct $(\mathrm{A})$ from isolated $\mathrm{C}_{60}$ and anthracene, formation of complex 1 (B) from two isolated $\mathrm{C}_{60}$ molecules and anthracene, interaction of $\mathrm{C}_{60}$ with the $\mathrm{C}_{60}$ :anthracene mono-adduct to form 1 (C), interaction of two $\mathrm{C}_{60}$ :anthracene mono-adducts to form 2 (D). Relative reaction free energies $(\Delta \mathrm{G})$ as well as relative electronic energies $(\Delta \mathrm{E})$ are given in $\mathrm{kJ} \mathrm{mol}^{-1}$ and were obtained with BP86/def2-TZVP/ D3//BP86/def2-SVP/D3. 


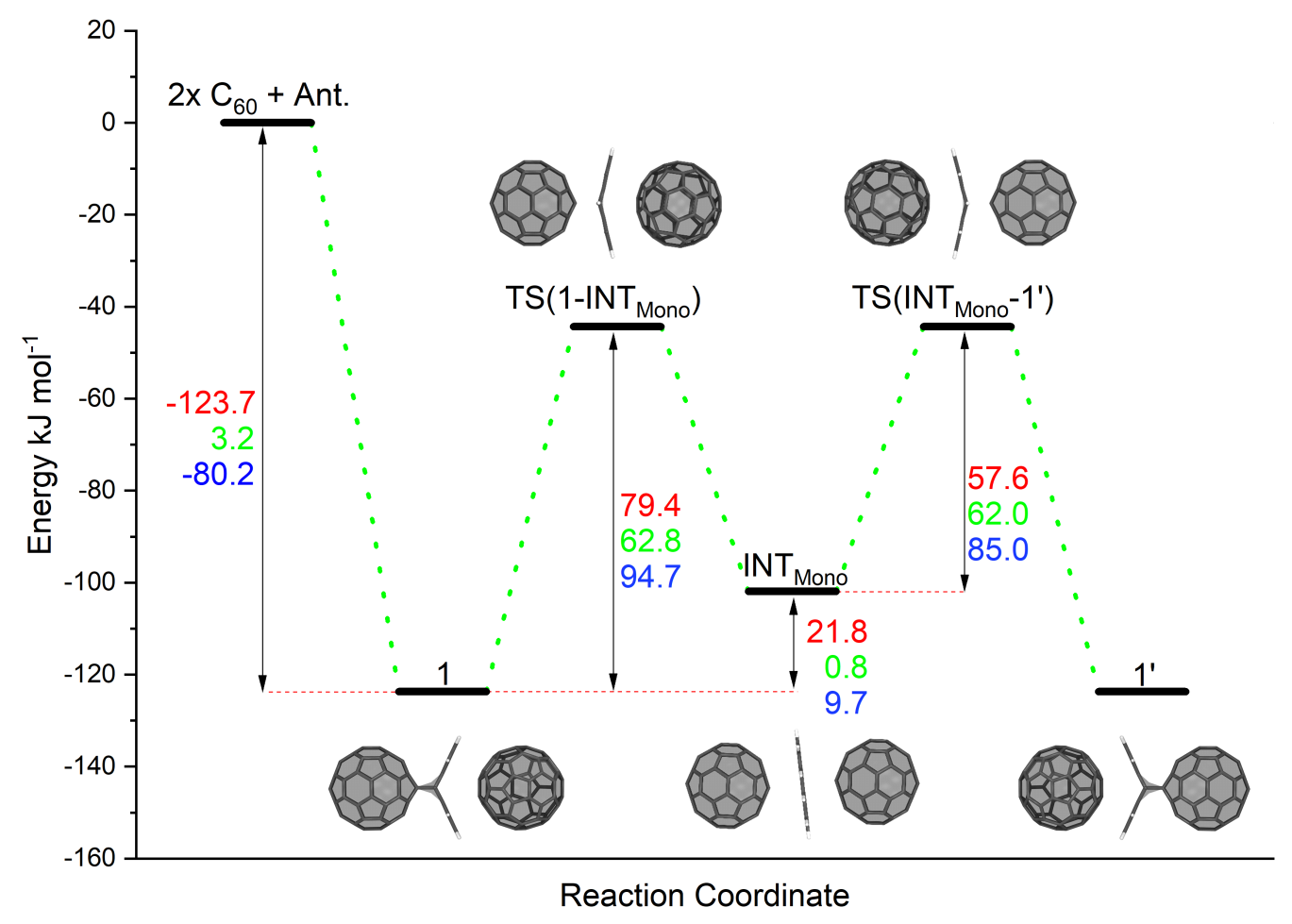

Figure 1. Reaction mechanism of the anthracene transfer (reaction A, see Scheme 1) from the $\mathrm{C}_{60}$ :anthracene mono-adduct ( see 1) to a neighboring $\mathrm{C}_{60}$ fullerene (see 1') in a two-step synchronous Retro Diels-Alder and Diels-Alder Reaction via a stacked intermediate (INT Mono). $_{\text {) }}$ Red values denote BP86/def2-TZVP/D3//BP86/def2-SVP/D3 relative electronic energies, green values denote reaction free energies and blue values denote relative electronic energies computed with B3LYP/def2-TZVP/D3//BP86/def2-SVP/D3. All values are in $\mathrm{kJ} \mathrm{mol}^{-1}$.

The proposed reaction pathway for the anthracene transfer as modelled by reaction A (see Scheme 1) is depicted in Figure 1, depicting educts, products, intermediates as well as transition states. Relative electronic energies (BP86/def2-TZVP/D3//BP86/def2-SVP/D3) are given in red and reaction free energies in green. For sake of comparison, B3LYP/def2-TZVP/D3//BP86/def2$\mathrm{SVP} / \mathrm{D} 3$ are listed in blue.

While the formation of complex $\mathbf{1}$, from two fullerenes and an anthracene molecule is energetically favored, the most stable conformation of $\mathbf{1}$ was determined by a potential energy scan of the rotation of the $2^{\text {nd }}$ fullerene as depicted in the S.I. in Figure S12. 
In the initial reaction step, complex 1 undergoes a Retro-Diels-Alder type process, in which the anthracene incompletely separates from the fullerene moiety. The transition state TS(1-INT Mono) for this reaction step has a barrier of $\Delta \mathrm{E}=79.4 \mathrm{~kJ} \mathrm{~mol}^{-1}, \Delta \mathrm{G}=62.8 \mathrm{~kJ} \mathrm{~mol}^{-1}$ and $\Delta \mathrm{E}_{\mathrm{B} 3 \mathrm{LYP}}=94.7 \mathrm{~kJ}$

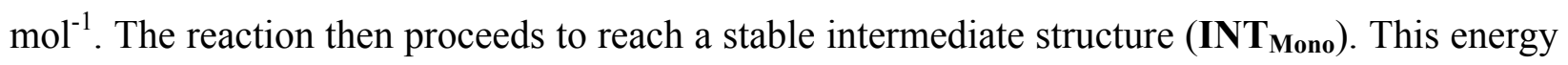
minimum structure is less stable than educt 1 , by $\Delta \mathrm{E}=21.8 \mathrm{~kJ} \mathrm{~mol}^{-1}\left(\Delta \mathrm{G}=0.8 \mathrm{~kJ} \mathrm{~mol}^{-1}\right.$, and $\Delta \mathrm{E}_{\mathrm{B} 3 \mathrm{LYP}}$ $=9.7 \mathrm{~kJ} \mathrm{~mol}^{-1}$ ). Remarkably, the anthracene molecule lies completely flat between the two fullerenes experiencing interactions with both sides. The reaction then continues in a mirrored fashion, with a [4+2] cycloaddition step. The second transition state, $\mathbf{T S}\left(\mathbf{I N T}_{\mathbf{M o n o}^{-1}}{ }^{\text {') }}\right.$, lies above the intermediate state, with $\Delta \mathrm{E}=57.6 \mathrm{~kJ} \mathrm{~mol}^{-1}, \Delta \mathrm{G}=62.0 \mathrm{~kJ} \mathrm{~mol}^{-1}$, and $\Delta \mathrm{E}_{\mathrm{B} 3 \mathrm{LYP}}=85.0 \mathrm{~kJ} \mathrm{~mol}^{-1}$, exhibiting energy values identical to the reversed reaction to $\mathbf{T S}\left(\mathbf{1 - I N T} \mathbf{I M n o}_{\text {Mo. The product }}\right.$ compound ( $\left.\mathbf{1}^{\prime}\right)$ is chemically identical to the educt $\mathbf{1}\left(\Delta \mathrm{E}=0.0 \mathrm{~kJ} \mathrm{~mol}^{-1}\right)$. Compared to BP86, for B3LYP somewhat higher electronic energies were found. Nevertheless, both are in good agreement with each other. 


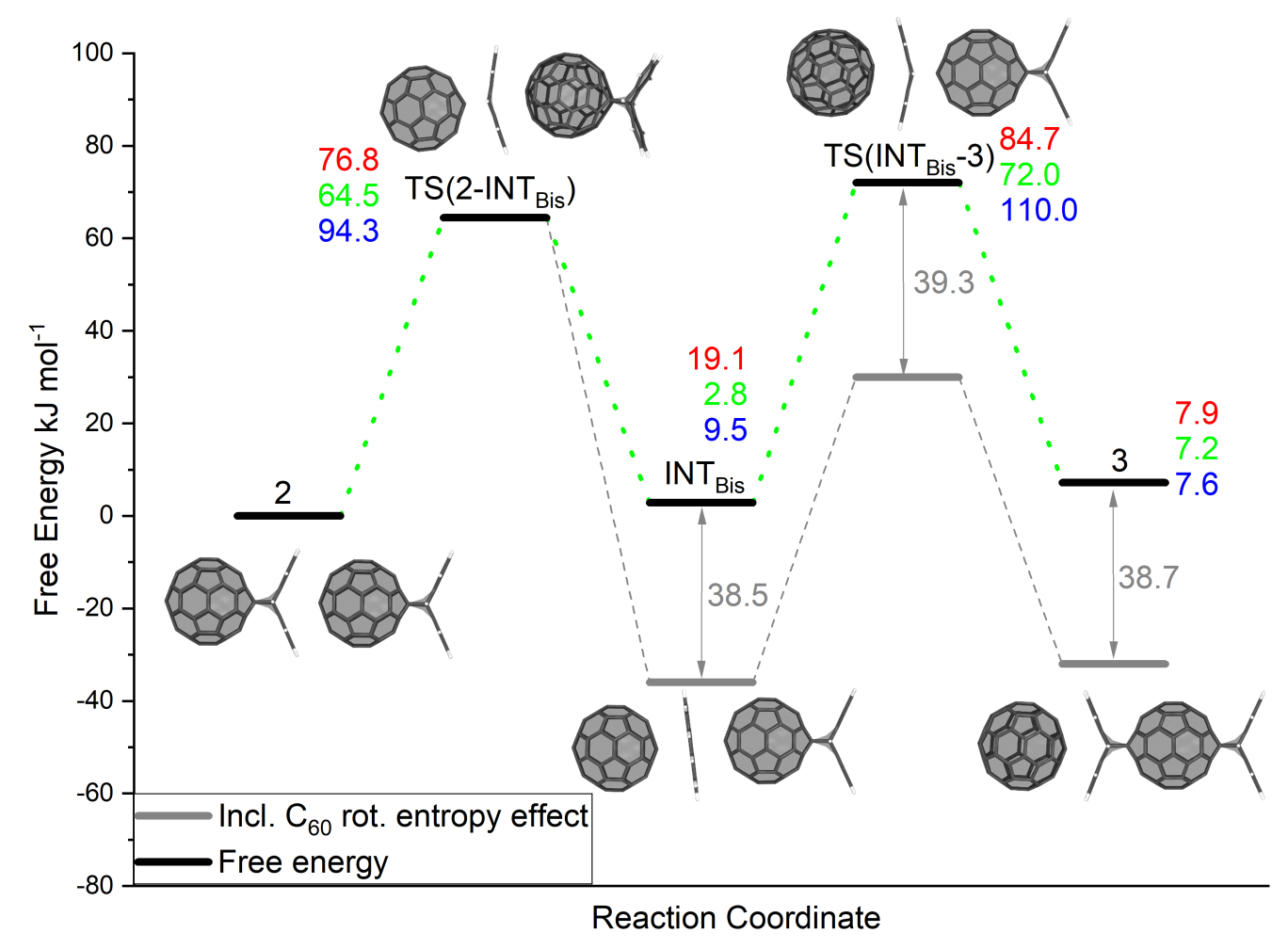

Figure 2. Reaction pathway of the anthracene transfer between two mono-adducts (reaction B). Electronic and reaction free energies calculated with BP86/def2-TZVP/D3//BP86/def2-SVP/D3 are depicted in red and green, respectively. Energies calculated with B3LYP/def2TZVP/D3//BP86/def2-SVP/D3 are shown in blue. The gray lines represent the free energy when additional rotational entropy of the $\mathrm{C}_{60}$ is taken into account too. All values are in $\mathrm{kJ} \mathrm{mol}^{-1}$.

In model reaction $\mathrm{B}$ (see also Scheme 2), structure 2, where two $\mathrm{C}_{60}$ :anthracene mono-adducts are aligned, reacts exclusively to the antipodal trans-bis-adduct in complex with $\mathrm{C}_{60}$ (denoted as 3) undergoing a proposed mechanism as depicted in Figure 2.

Similar as in reaction A, the mechanism starts with an incomplete dissociation of one anthracene molecule in a retro Diels Alder step to yield the stable intermediate $\mathbf{I N T}_{\mathbf{B i s}}$, where the anthracene is trapped between two fullerenes. For this reaction step an energy barrier of $\Delta \mathrm{E}=76.8 \mathrm{~kJ} \mathrm{~mol}^{-1}$ $\left(\Delta \mathrm{G}=64.5 \mathrm{~kJ} \mathrm{~mol}^{-1}\right.$ and $\left.\Delta \mathrm{E}_{\mathrm{B} 3 \mathrm{LYP}}=94.3 \mathrm{~kJ} \mathrm{~mol}^{-1}\right)$ was found, being very similar to the corresponding 
energy barrier in reaction $\mathrm{A}$. The intermediate ( $\mathbf{I N T}_{\text {Bis }}$ ) has a relative electronic energy $\Delta \mathrm{E}=19.1$ $\mathrm{kJ} \mathrm{mol}^{-1}\left(\Delta \mathrm{E}_{\mathrm{B} 3 \mathrm{LYP}}=9.5 \mathrm{~kJ} \mathrm{~mol}^{-1}\right)$ and a free energy of $\Delta \mathrm{G}=2.8 \mathrm{~kJ} \mathrm{~mol}^{-1}$, indicating the stabilizing effect of the neighboring fullerenes on the anthracene. $\mathbf{I N T}_{\text {Bis }}$ then reaches a $2^{\text {nd }}$ transition state $\mathbf{T S}\left(\mathbf{I N T}_{\mathbf{B i s}^{-}} \mathbf{3}\right)$ with a relative energy of $\Delta \mathrm{E}=84.7 \mathrm{~kJ} \mathrm{~mol}^{-1}$, a relative free energy of $\Delta \mathrm{G}=72.0 \mathrm{~kJ}$ $\mathrm{mol}^{-1}\left(\Delta \mathrm{E}_{\mathrm{B} 3 \mathrm{LYP}}=110.0 \mathrm{~kJ} \mathrm{~mol}^{-1}\right)$ en route to forming the antipodal bisadduct in complex with $\mathrm{C}_{60}$, denoted as 3. The $2^{\text {nd }}$ transition state is less favorable than $\mathbf{T S}\left(\mathbf{2}-\mathbf{I N T}_{\mathbf{B i s}}\right)$, but the barrier is with $\Delta \mathrm{E}=65.6 \mathrm{~kJ} \mathrm{~mol}^{-1}\left(\Delta \mathrm{G}=69.2 \mathrm{~kJ} \mathrm{~mol}^{-1} \Delta \mathrm{E}_{\mathrm{B} 3 \mathrm{LYP}}=100.4 \mathrm{~kJ} \mathrm{~mol}^{-1}\right)$ slightly lower due to the higher energy of $\mathbf{I N T}_{\text {Bis. }}$. In the initial calculations, the formed antipodal $\mathbf{C}_{60}$ :anthracenes bis-adduct in complex with $\mathrm{C}_{60}(3)$ is with a relative electronic energy of $7.9 \mathrm{~kJ} \mathrm{~mol}^{-1}\left(\Delta \mathrm{G}=7.2 \mathrm{~kJ} \mathrm{~mol}^{-1}\right.$ and $\Delta \mathrm{E}_{\mathrm{B} 3 \mathrm{LY}}=7.6 \mathrm{~kJ} \mathrm{~mol}^{-1}$ ) thermodynamically slightly less favored than 2 . However, as shown by low barrier to rotation of the $\mathrm{C}_{60}$ moiety in $\mathbf{1}$ (see Figure $\mathrm{S} 12$ ), a hindered rotation of $\mathrm{C}_{60}$ in $\mathbf{I N T}_{\text {Bis, }}$, TS(INT $\left.{ }_{\text {Bis }}-\mathbf{3}\right)$ and $\mathbf{3}$ can be anticipated, resulting in additional rotational entropy, which lowers the total free energy by about $38-39 \mathrm{~kJ} \mathrm{~mol}^{-1}$ for each of these structures.

To further analyze the reaction, we used the distortion interaction model/activation strain model independently developed by Houk and Bickelhaupt $\mathrm{t}^{93,118,119}$ to characterize all stationary points in the reaction including intermediates and product/educt structures. As results are expected to be similar, we restrict our analyses to reaction A only.

We intend to quantify the effects of the deformations exerted by the weaker, non-covalent interactions and to characterize the planar anthracene molecule in the intermediate structures. In our distortion interaction analysis along the reaction coordinate, the interactions on both sides of the anthracene were considered by taking the unperturbed fullerene and anthracene molecule as reference structures.

Table 1. Distortion-Interaction energies for reaction A. $\Delta \mathrm{E}_{\mathrm{C} 60 \text { Def. }}$ represents the total energy difference of the two fullerenes, when compared with a reference structure represented by two fullerenes and one anthracene which are infinitely separated; $\Delta \mathrm{E}_{\text {Anthracene Def }}$ represents the total energy difference of the anthracene, when compared with a reference structure - free molecule; $\Delta \mathrm{E}_{\text {Total Def }}$ represents the sum of all deformation energies; $\Delta \mathrm{E}_{\text {Total Int }}$ represents the difference 
between the electronic energy and the total deformation; $\Delta \mathrm{E}_{\text {Electronic }}$ represents the electronic energy of the structure with reference to isolated $\mathrm{C}_{60}$ fullerene and anthracene molecules.

\begin{tabular}{|c|c|c|c|c|c|}
\hline Structure & 1 & TS(1-INT Mono $)$ & INT $_{\text {Mono }}$ & TS(INT $_{\text {Mono }}$-1') $\left.^{\prime}\right)$ & $1 '$ \\
\hline$\Delta \mathbf{E}_{\mathbf{C 6 0} \text { Def. }}$ & 174.3 & 48.4 & 18.5 & 48.4 & 174.3 \\
\hline$\Delta \mathbf{E}_{\text {Anthracene Def. }}$ & 306.8 & 86.0 & 3.2 & 86.0 & 306.8 \\
\hline$\Delta \mathbf{E}_{\text {Total Def. }}$ & 481.1 & 134.4 & 21.7 & 134.4 & 481.1 \\
\hline$\Delta \mathbf{E}_{\text {Total Int. }}$ & -583.6 & -157.6 & -102.4 & -157.6 & -583.6 \\
\hline$\Delta \mathbf{E}_{\text {Electronic }}$ & -102.5 & -23.1 & -80.7 & -23.1 & -102.5 \\
\hline
\end{tabular}

When looking at the deformation energies for the $\mathrm{C}_{60}$ fullerene along the reaction coordinate of reaction $\mathrm{A}$ as listed in Table 1, a maximum of $\Delta \mathrm{E}_{\mathrm{C} 60 \text { Def. }}=174.3 \mathrm{~kJ} \mathrm{~mol}^{-1}$ was found in $\mathbf{1}$ and $\mathbf{1}$, decreasing to $48.4 \mathrm{~kJ} \mathrm{~mol}^{-1}$ in the transition states and reaching a minimum in the intermediate INT $_{\text {Mono. }}$. A mere deformation of $\Delta \mathrm{E}_{\mathrm{C} 60 \text { Def. }}=18.5 \mathrm{~kJ} \mathrm{~mol}^{-1}$ indicate that the structure is close to that of an unperturbed $\mathrm{C}_{60}$ fullerene. The same trend was observed for the deformation of anthracene. Of course, the strong deformations of bound anthracene are alleviated upon reaching the TS. However remarkably, $\mathbf{I N T}_{\text {Mono }}$ has a very small anthracene deformation energy of only $\Delta \mathrm{E}_{\text {Anthracene }}$ Def. $=3.2 \mathrm{~kJ} \mathrm{~mol}^{-1}$, indicating that the anthracene is stabilized almost at its ideal gas phase geometry. The total deformation energy is, therefore, by far the smallest in $\mathbf{I N T}_{\text {Mono }}$ (in total: $21.7 \mathrm{~kJ} \mathrm{~mol}^{-1}$ ). In comparison to the other species, the stability of the $\mathbf{I N T}_{\mathbf{M o n o}}$ is thus mainly govern by minimal distortion because its interaction energy $\Delta \mathrm{E}_{\text {Total Int. is significantly smaller than in all other }}$ structures. Still, this unique interplay of distortion and interaction results in a striking stabilization of $\mathbf{I N T}_{\text {Mono }}$ in unprecedented 'inverted sandwich' structure with $\Delta \mathrm{E}_{\text {Electronic }}=-80.7 \mathrm{~kJ} \mathrm{~mol}^{-1}$, when assembled from two fullerenes and an anthracene. 
Structure and electronic properties of the intermediate INT $T_{M o n o}$

To shed light on the nature of the unprecedented intermediates, $\mathbf{I N T}_{\text {Mono }}$ and INT $_{\text {Bis, }}$, where the anthracene lies almost perfectly planar between the two curved fullerenes, potential energy surfaces as well as non-covalent interactions were investigated.

Two 2D potential energy surface scans were performed at the example of $\mathbf{I N T}_{\text {Mono, }}$, see Figure 3. On the left-hand side (A.), the PES for the displacement of the left $\mathrm{C}_{60}$ fullerene along the $y$-axis and its rotation around the $x$-axis is depicted. On the right-hand side (B.), the rotation of the anthracene around the $x$-axis and its tilt, i.e., its rotation around the $z$-axis is shown. As evident from the plot, the potential energy surface is rather flat allowing for a wide range of motion of the anthracene and fullerene without significant increase in energy. For example, given an energy increase up to $10.0 \mathrm{~kJ} \mathrm{~mol}^{-1}$, the fullerene can rotate by $\sim 80^{\circ}$ and can be displaced along the $y$-axis by $\pm 0.4 \AA$ (Figure $3 \mathrm{~A}$.). Despite being rather flat, the energy minimum - verified by analysis of the harmonic frequencies - was determined for a conformation, where - compared to an idealized $\mathrm{C}_{2 v}$ symmetric complex - the anthracene is rotated by $32.5^{\circ}$ around the $x$-axis and tilted, i.e., rotated around the $z$-axis by $8^{\circ}$ and the two fullerenes are oriented with their center of mass above and below the $x z$-plane (see Figure 3). Consequently, this inverted sandwich stabilization of the anthracene by the two neighbouring fullerenes is the orientation, where (non-covalent) interactions are most favourable. While the attractive dispersion corrections become more favourable when the anthracene-fullerene distance is minimized (see $x$-axis in the dispersion energy surface shown in Figure $3 \mathrm{C}$ ), it can also be seen that dispersive interactions depend on the rotation of the fullerene (see $y$-axis in Figure 3C).

We also tested replacement of anthracene by smaller rings such as naphthalene and benzene in

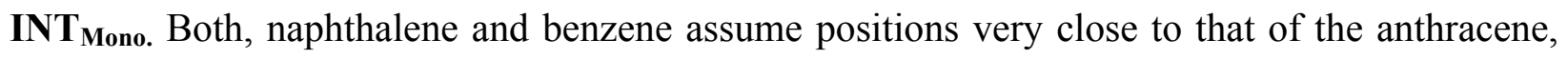
being tilted by $8^{\circ}$ (rotated by $8^{\circ}$ around the $z$-axis) and rotated by $32.5^{\circ}$ around the $x$-axis, even though the arrangement of the acene over the ring slightly differs (see Figure S15 S.I.). 

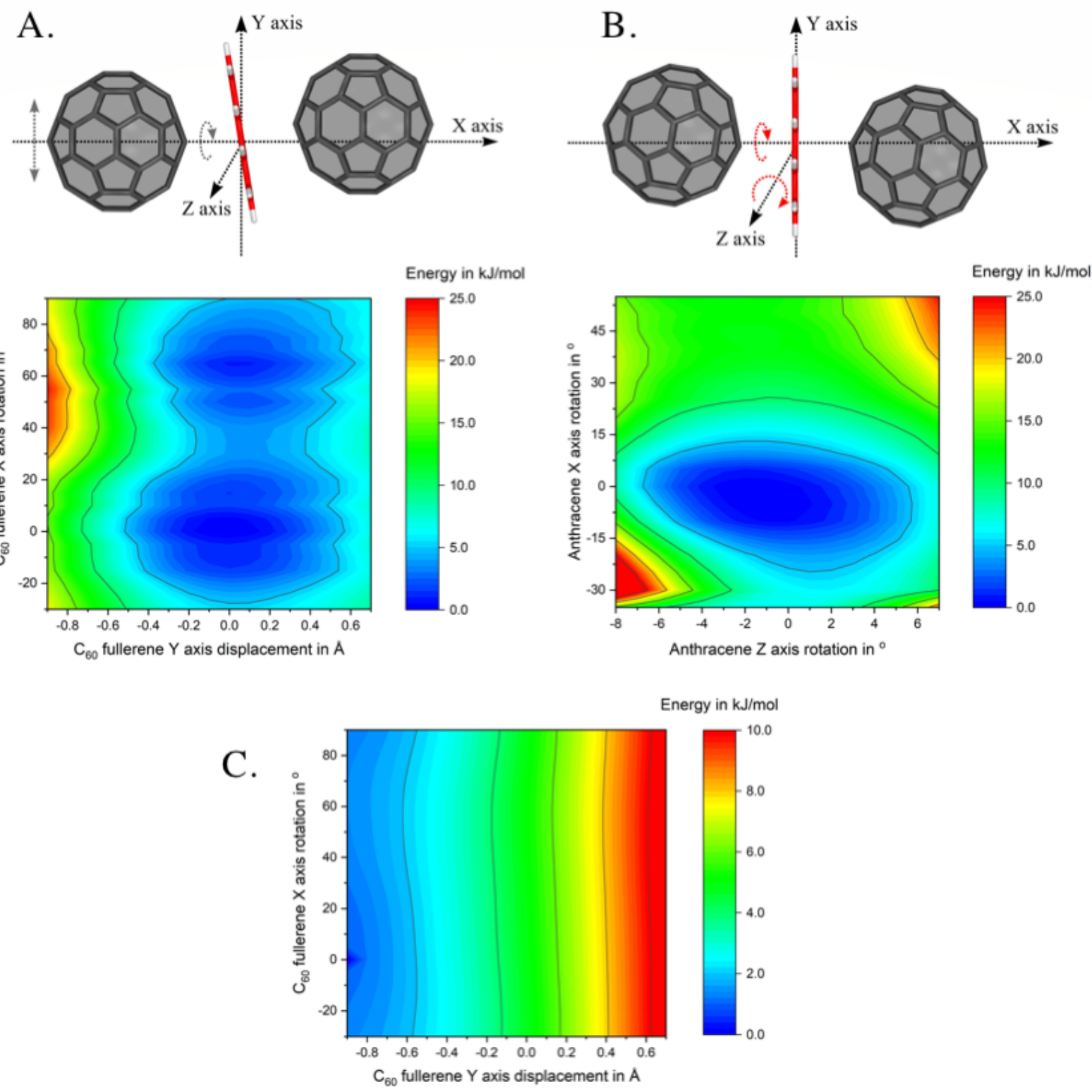

Figure 3. 2D potential energy surfaces scans of the intermediate $\mathbf{I N T}_{\text {Mono. }}$ A. The $\mathrm{C}_{60}$ is rotated around the $x$-axis by $-30^{\circ}$ and $+90^{\circ}$ and displaced along the $y$-axis by +0.9 and $-0.7 \AA$ relative to the

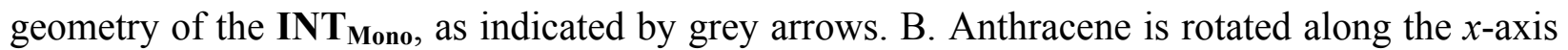

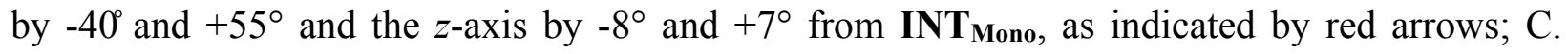
Relative empirical dispersion corrections for the PES scan depicted in A. Displayed energies are given in $\mathrm{kJ} \mathrm{mol}^{-1}$, calculated with BP86/def2-SVP/D3. 
To further elucidate the interactions between the anthracene and their two neighbouring fullerenes, the non-covalent interactions were visualized using NCIPlot as depicted in Figure 4. ${ }^{115,116}$ Here, the electronic density is examined as a function of an isosurface of the reduced gradient, thus allowing for a quantitative assessment on the non-covalent interactions. Red areas in Figure 4 denote strong repulsive interaction, whereas green denote weakly attractive regions, typical for van der Waals interactions or dispersive interactions. These are found between the upper and middle $\mathrm{C}_{6}$-ring of anthracene and the closest $\mathrm{C}_{6}$-ring of the left fullerene as well as between the middle and lower $\mathrm{C}_{6}$-ring of anthracene and the closest $\mathrm{C}_{6}$-ring of the right fullerene, showing symmetric $\pi-\pi$ double decker interactions in this 'inverted sandwich' structure.
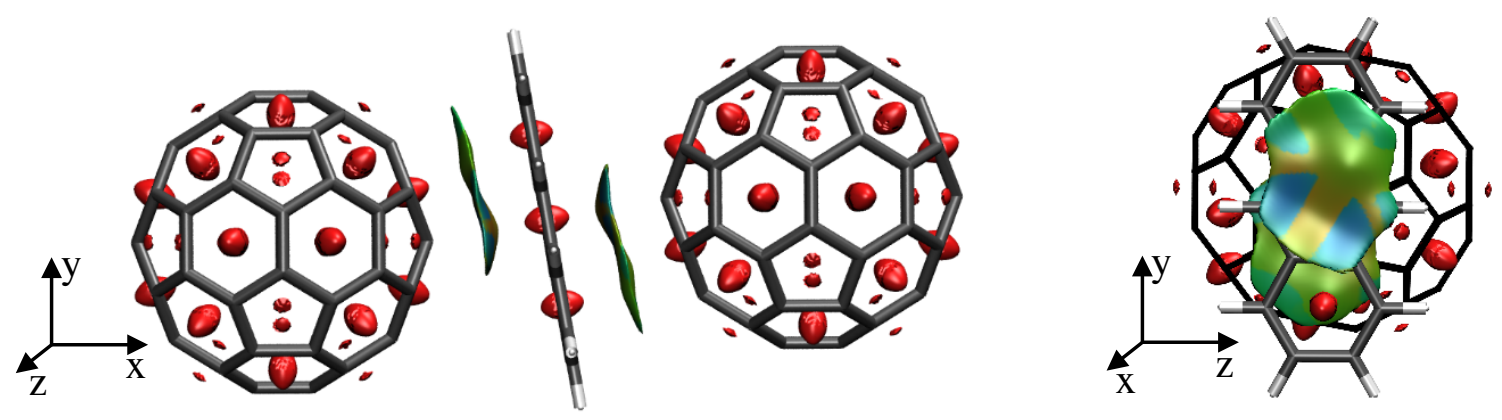

Figure 4. Interactions between the $\mathrm{C}_{60}$ fullerenes and the anthracene molecule in the $\mathbf{I N T}_{\text {mono }}$ structure, plotted as an isosurface of the reduced density gradient $s$. Left: side view of INT $_{\text {mono; }}$; Right: Transversal view of $\mathbf{I N T}_{\text {Mono. }}$. An isosurface of $s=0.3$ a.u. is depicted and the colors from blue to red correspond to $\operatorname{sign}\left(\lambda_{2}\right) \rho$, values from -0.1 to 0.1 a.u.

\section{Characterization of transition states}

To evaluate the effect of a second fullerene or $\mathrm{C}_{60}$ :anthracene on the transition state for the cycloaddition or cycloreversion, we analyzed the structural and electronic effects in the obtained transition states $\mathbf{T S}\left(\mathbf{I N T}_{\text {Bis }}-\mathbf{3}\right)$, $\mathbf{T S}\left(\mathbf{2}-\mathbf{I N T}_{\text {Bis }}\right)$, and $\mathbf{T S}\left(\mathbf{1}-\mathbf{I N T}_{\text {Mono }}\right)$ and compared them to a number of $\mathrm{C}_{60}$ :arene cycloaddition/cycloreversion transition states. 

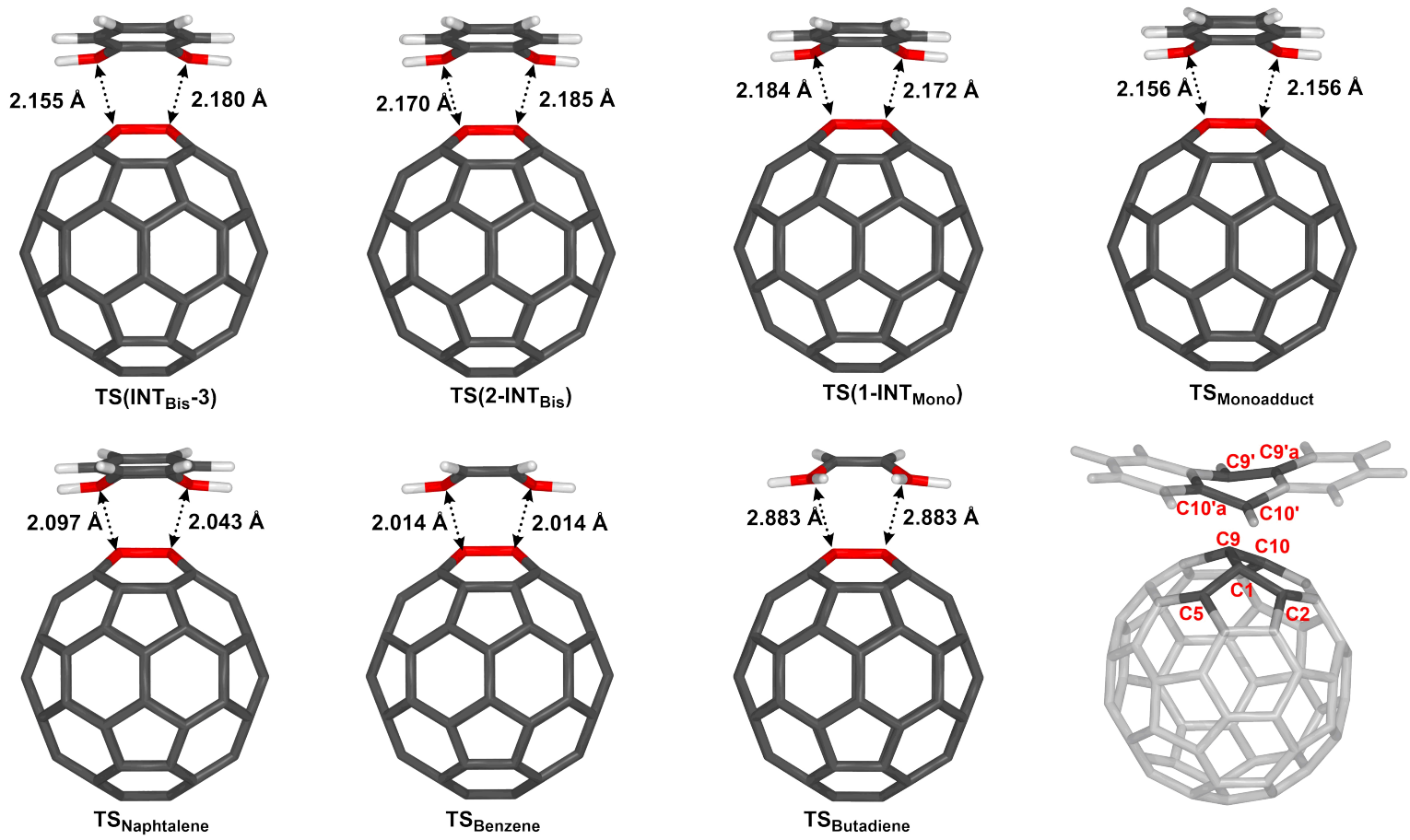

Figure 5. Comparison of various transition state structures: $\mathbf{T S}\left(\mathbf{I N T}_{\mathbf{B i s}}-\mathbf{3}\right), \mathbf{T S}\left(\mathbf{2}-\mathbf{I N T}_{\mathrm{Bis}}\right)$, and

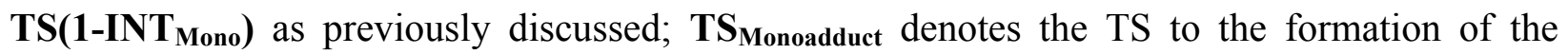
$\mathrm{C}_{60}$ :anthracene monoadduct, $\mathbf{T S}_{\mathbf{N a p h t a l e n e}}$ and $\mathbf{T} \mathbf{S}_{\text {Benzene }}$ denote the TS to the formation of the $\mathrm{C}_{60}$ :naphthalene and $\mathrm{C}_{60}$ :benzene monoadducts, whereas $\mathbf{T S}_{\text {Butadiene }}$ denotes the $\mathrm{TS}$ for the reaction of butadiene with $\mathrm{C}_{60}$. Numbering of structures according to IUPAC. Structures were fully optimized with BP86/def2-SVP/D3. 
Table 2. Relevant structural parameters of different transition states involved in $\mathrm{C}_{60}$ functionalization. Distances are given in $\AA$, angles, and dihedrals in ${ }^{\circ} . \Delta \mathrm{E}_{\text {Barrier }}$ represents the energy barrier between the noncovalently bound intermediate (see Figure S16 for structures) and their respective transition state in $\mathrm{kJ} \mathrm{mol}^{-1}$ calculated as single points (BP86/def2-TZVP/D3) on the fully optimized BP86/def2-SVP/D3 structures.

\begin{tabular}{|c|c|c|c|c|c|c|c|}
\hline Structure & $\begin{array}{l}\text { TS(INT } \text { Bis- }^{-} \\
\text {3) }\end{array}$ & $\begin{array}{l}\text { TS(2- } \\
\left.\text { INT }_{\text {Bis }}\right)\end{array}$ & $\begin{array}{l}\text { TS(1- } \\
\left.\text { INT }_{\text {Mono }}\right)\end{array}$ & $\mathbf{T S}_{\text {Monoadduct }}$ & $\mathbf{T S}_{\text {Naphtalene }}$ & $\mathbf{T S}_{\text {Benzene }}$ & $\mathbf{T S}_{\text {Butadiene }}$ \\
\hline \multicolumn{8}{|l|}{ Bond Lengths } \\
\hline C1-C10' & 2.180 & 2.185 & 2.184 & 2.156 & 2.097 & 2.014 & 2.883 \\
\hline C9-C9' & 2.155 & 2.170 & 2.172 & 2.156 & 2.043 & 2.014 & 2.884 \\
\hline $\mathrm{C} 1-\mathrm{C} 5$ & 1.485 & 1.483 & 1.484 & 1.485 & 1.493 & 1.497 & 1.479 \\
\hline $\mathrm{C} 1-\mathrm{C} 9$ & 1.480 & 1.482 & 1.482 & 1.483 & 1.482 & 1.481 & 1.480 \\
\hline \multicolumn{8}{|l|}{ Angles } \\
\hline $\mathrm{C} 5-\mathrm{C} 1-\mathrm{C} 2$ & 104.5 & 104.7 & 104.7 & 104.5 & 103.7 & 103.4 & 105.3 \\
\hline $\mathrm{C} 5-\mathrm{C} 1-\mathrm{C} 9$ & 117.6 & 117.8 & 117.7 & 117.6 & 116.8 & 117.0 & 118.3 \\
\hline \multicolumn{8}{|l|}{ Dihedral Angles } \\
\hline C5-C1-C9-C10 & 126.8 & 126.8 & 126.9 & 126.2 & 124.5 & 123.4 & 129.0 \\
\hline $\begin{array}{l}\text { C10'a-C10'-C9'- } \\
\text { C9'a }\end{array}$ & 147.8 & 147.8 & 148.4 & 148.6 & 144.9 & 143.0 & - \\
\hline$\Delta E_{\text {Barrier }}$ & 65.6 & 57.7 & 57.6 & 62.4 & 100.9 & 128.1 & 30.5 \\
\hline
\end{tabular}

Most notable differences in the transition states can be seen in the C1-C10' and C9-C9' bond lengths. With $\mathbf{T S}_{\text {Butadiene }}$ being a somewhat different case due to the absence of an aromatic ring, it can be seen the C1-C10' and the C9-C9' bond lengths increase with increasing ring size and 
further increases in the presence of a $2^{\text {nd }}$ fullerene. In addition, the transition states become more

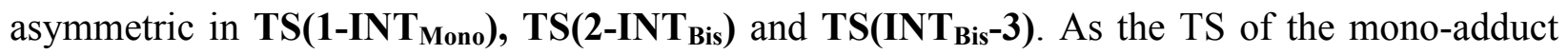
and of the antipodal bis-adduct (see S.I. Figure S7) are almost perfectly symmetric, this asymmetry likely arises due to interaction with the $2^{\text {nd }}$ fullerene, which is aligned slightly off axis.

Considering the energy barriers, when the non-covalently bound intermediate is taken as a reference (see Figure S16 for structures), it can be seen than TS(1-INT Mono) and TS(2-INT $_{\text {Bis }}$ ) not only have very similar barrier heights but also the lowest energy barriers for this set of structures (57.6 and $57.7 \mathrm{~kJ} \mathrm{~mol}^{-1}$ ), once more hinting towards the contribution of the $2^{\text {nd }}$ fullerene in this reaction. The formation of the bis-adduct in $\mathbf{T S}\left(\mathbf{I N T}_{\mathbf{B i s}} \mathbf{- 3}\right)$ has a higher energy barrier with $\Delta \mathrm{E}_{\text {Barrier }}$ $=65.6 \mathrm{~kJ} \mathrm{~mol}^{-1}$ as expected and very similar to that of the antipodal bis-adduct $\left(67.2 \mathrm{~kJ} \mathrm{~mol}^{-1}\right.$, see S. I. Table S2), slightly surpassing the activation energy necessitated by the formation of the $\mathrm{C}_{60}$ :anthracene mono-adduct at $\Delta \mathrm{E}_{\text {Barrier }}=62.4 \mathrm{~kJ} \mathrm{~mol}^{-1}$. The energy barrier for the formation of mono-adducts increases as the diene gets smaller, $\Delta \mathrm{E}_{\text {Barrier }}=100.9 \mathrm{~kJ} \mathrm{~mol}^{-1}$ for $\mathrm{TS}_{\text {naphtalene }} 128.1$ $\mathrm{kJ} \mathrm{mol}^{-1}$ for $\mathrm{TS}_{\text {benzene, }}$ with the notable exception of $\mathrm{TS}_{\text {butadiene, }}$ where the energy is the lowest out of all investigated transition states, at only $30.5 \mathrm{~kJ} \mathrm{~mol}^{-1}$.

We also performed a distortion-interaction analysis ${ }^{93,118,119}$ on the transition states depicted in Figure 5, for details see illustration in Figure S13 in the Supporting Information. It can be seen from Table 3, that the total deformation energy is smallest $\left(115.9\right.$ and $\left.113.6 \mathrm{~kJ} \mathrm{~mol}^{-1}\right)$ for the two transition states $\mathbf{T S}\left(\mathbf{2}-\mathbf{I N T}_{\mathbf{B i s}}\right)$ and $\mathbf{T S}\left(\mathbf{1}-\mathbf{I N T}_{\mathbf{M o n}}\right)$, where a $\mathrm{C}_{60}$ : anthracene mono-adduct is formed in the presence of a second fullerene. The deformation energy increases slightly when we look at the mono-adduct, at $119.2 \mathrm{~kJ} \mathrm{~mol}^{-1}$ as well as when reducing the size of the added molecule. Thus, it reaches $159.2 \mathrm{~kJ} \mathrm{~mol}^{-1}$ naphthalene for and $186.6 \mathrm{~kJ} \mathrm{~mol}^{-1}$ for benzene. Butadiene, requires a minimal amount of deformation energy compared to the other transition states, with a total of 67.7 $\mathrm{kJ} \mathrm{mol}^{-1}$. The interaction energy of the transfer reactions is consistent amongst all transition states involving aromatic hydrocarbons showing little variation, with $\mathbf{T S}\left(\mathbf{I N T}_{\mathbf{B i s}} \mathbf{- 3}\right)$ having the least favorable energy, $-52.4 \mathrm{~kJ} \mathrm{~mol}^{-1}$, and $\mathbf{T S}\left(\mathbf{2}-\mathbf{I N T}_{\mathbf{B i s}}\right)$ the most favorable one, at $-58.3 \mathrm{~kJ} \mathrm{~mol}^{-1}$. The deformation energy largely correlates with the barrier height with the exception of $\left.\operatorname{TS}_{(\mathbf{I N T}} \mathbf{T i s}_{\mathbf{B i}} \mathbf{3}\right)$, where the less favorable interaction energy and higher $\mathrm{C}_{60}$ deformation energy can be considered the cause for the high transition-state energy. 
Table 3. Distortion-Interaction energies for the transition states depicted in Figure 5. $\Delta \mathrm{E}_{\mathrm{C} 60 \text { Def }}$ represents the deformation energy of the fullerene/ $\mathrm{C}_{60}$ :anthracene monoadduct, when compared with the corresponding intermediate $\mathrm{C}_{60}$ fullerene/ $\mathrm{C}_{60}$ :anthracene monoadduct structure; $\Delta \mathrm{E}_{\text {Diene }}$ Def. represents the total energy difference of the diene, when compared with the corresponding intermediate structure molecule; $\Delta \mathrm{E}_{\text {Total Def. }}$ represents the sum of all deformation energies; $\Delta \mathrm{E}_{\text {Total }}$ Int. represents the difference between the barrier energy and the total deformation; $\Delta \mathrm{E}_{\text {Barrier }}$ represents the electronic energy difference between the transition state and the corresponding intermediate structure.

\begin{tabular}{|c|c|c|c|c|c|c|c|}
\hline Structure & TS(INT $\left.{ }_{\text {Bis }}-3\right)$ & TS $\left(2-I_{N T} T_{B i s}\right)$ & TS(1-INT Mono $)$ & $\mathbf{T S}_{\text {Monoadduct }}$ & $\mathbf{T S}_{\text {Naphtalene }}$ & $\mathbf{T S}_{\text {Benzene }}$ & $\mathbf{T S}_{\text {Butadiene }}$ \\
\hline$\Delta \mathbf{E}_{\mathbf{C 6 0} \text { Def. }}$ & 32.8 & 32.5 & 30.8 & 34.9 & 45.2 & 53.3 & 17.6 \\
\hline$\Delta \mathbf{E}_{\text {Diene Def. }}$ & 85.2 & 83.5 & 82.8 & 84.3 & 114.0 & 133.4 & 50.1 \\
\hline$\Delta \mathbf{E}_{\text {Total Def. }}$ & 118.0 & 115.9 & 113.6 & 119.2 & 159.2 & 186.6 & 67.7 \\
\hline$\Delta \mathbf{E}_{\text {Total Int. }}$ & -52.4 & -58.3 & -56.0 & -56.8 & -58.3 & -58.3 & -37.2 \\
\hline$\Delta \mathbf{E}_{\text {Barrier }}$ & 65.6 & 57.7 & 57.6 & 62.4 & 100.9 & 128.3 & 30.5 \\
\hline
\end{tabular}

\section{DISCUSSION}

\section{Reaction mechanism}

Both investigated reaction A and B (see Scheme 1) follow a synchronous two-step retro DA/DA sequence, where the anthracene incompletely dissociates and is trapped between to fullerenes during the entire reaction to yield a regiospecific di-functionalization.

The starting point of reaction $\mathrm{A}$ is represented by a stabilized complex, $\mathbf{1}$, consisting of a $\mathrm{C}_{60}$ fullerene and $\mathrm{C}_{60}$ :anthracene mono-adduct. The interactions between the mono-adduct and the fullerene, while being favorable, allow for a large rotational movement of the $\mathrm{C}_{60}$ fullerene as the potential energy surface is very shallow. This indicates that a pre-alignment in the first reaction 
step is not immanent to the structures, but facilitated due to the confined arrangement of molecules in the solid state.

By comparing the transition states of reactions A and B, TS(INT $\left.{ }_{\text {Bis }}-3\right)$, TS(2-INT Bis $\left._{3}\right)$, and TS(1-

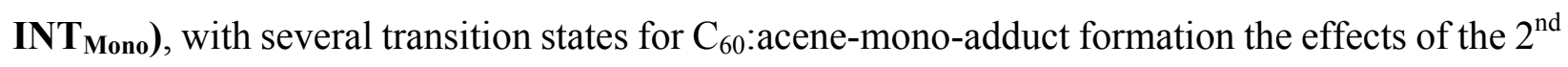
fullerene becomes apparent: (I) It elongates C1-C10' and C9-C9' bond and also induced a difference in the two bond lengths resulting in more asymmetric the transition states. Most likely this effect arises because the $2^{\text {nd }}$ fullerene is located off center the anthracene-fullerene axis but whether this is a result of the gas phase calculation and whether this also pertains the solid state remains speculative. (II) Its presence decreases the transition-barrier height mostly by decreasing the deformation.

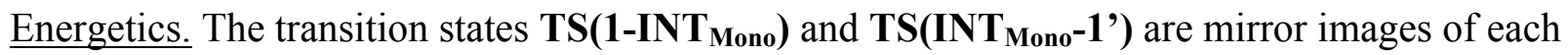
other with an energy barriers of $\Delta \mathrm{G}=\sim 60 \mathrm{~kJ} \mathrm{~mol}^{-1}$. In agreement with other studies on mono adducts, these are concerted transition states as indicated by their symmetric structures. ${ }^{106}$ Finding identical barriers for both the retro Diels-Alder reaction to form the intermediate $\mathbf{I N T}_{\mathbf{M o n o}}$ and the Diels-Alder reaction to form 1', is in contrast to experimental and theoretical studies of the $\mathrm{C}_{60}$ :anthracene mono adduct formation, where the retro Diels-Alder reaction is found to have a significantly higher barrier ${ }^{25,106}$ emphasizing once more the effect of the $2^{\text {nd }}$ fullerene.

The reaction rates and the half-life can be calculated using the Eyring equation:

$$
\begin{aligned}
& k=\frac{\kappa k_{B} \cdot T}{h} \cdot e^{-\frac{\Delta G}{R T}} \\
& t_{1 / 2}=\frac{\ln 2}{k}
\end{aligned}
$$

where $\mathrm{k}$ is the reaction rate, $\kappa$ is the transmission coefficient, here equal to one, $\mathrm{k}_{\mathrm{B}}$ is the Boltzmann constant, $\mathrm{h}$ is the Planck constant, $\Delta \mathrm{G}$ is the free energy barrier, $\mathrm{R}$ is the gas constant and $\mathrm{T}$ is the temperature in Kelvin.

At room temperature, for reaction A reaction rate of $6.2 \times 10^{1} \mathrm{~s}^{-1}$ is obtained $\left(t_{1 / 2}=1.1 \times 10^{-5} \mathrm{~s}\right)$, while heated up to $180^{\circ} \mathrm{C}$ the reaction rate increases to $k=5.4 \times 10^{5} \mathrm{~s}^{-1}\left(t_{1 / 2}=1.3 \times 10^{-9} \mathrm{~s}\right)$. Similar values are found for reaction $\mathrm{B}, k=4.8 \mathrm{~s}^{-1}\left(\mathrm{t}_{1 / 2}=1.5 \times 10^{-1} \mathrm{~s}\right)$ at room temperature and $k=1.0 \times 10^{5} \mathrm{~s}^{-}$ ${ }^{1}\left(t_{1 / 2}=6.9 \times 10^{-9} \mathrm{~s}\right)$ at $180^{\circ} \mathrm{C}$. This agrees with the experimentally observed fast reaction at elevated temperatures and shows that the reaction model is indeed plausible. ${ }^{120}$

Concerning reaction B, our initial calculations showed structure $\mathbf{3}$ is slightly less table than the educts. However thermodynamic corrections are calculated with the standard rigid rotator 
model/harmonic oscillator model of the entire complex 3. In this model, the rotational entropy is calculated for the whole complex not allowing for individual rotation of the $\mathrm{C}_{60}$ fullerene. This argument holds not only for $\mathbf{3}$ but also for $\mathbf{I N T}_{\mathbf{B i s}}$ and $\mathbf{T S}\left(\mathbf{I N T}_{\mathbf{B i s}} \mathbf{- 3}\right)$, whereas rotation is expected to be hindered in $\mathbf{2}$, due to crystal packing, and in $\mathbf{T S}\left(\mathbf{2}-\mathbf{I N T}_{\mathbf{B i s}}\right)$, where the fullerene still interacts with the anthracene.

If we assume the $\mathrm{C}_{60}$ fullerene to be freely rotating, the additional rotational entropy lowers $\Delta \mathrm{G}$ of INT $_{\text {Bis, }}$ TS(INT Bis $\left.\mathbf{3}\right)$, and 3 by max. 38-39 $\mathrm{kJ} \mathrm{mol}^{-1}$ making it thermodynamically favored. However, this is an upper limit for an unhindered rotation and the actual value is expected to be smaller. In any case, the correction to the standard model makes 3 the thermodynamically favored product of reaction $\mathrm{B}$. Of course, this also holds for reaction A, but the effect is symmetric and does not affect the relative energy difference between the structures.

Regiospecificity. In the experimental solid-state reaction, exclusively the formation of the antipodal bis-adduct and free $\mathrm{C}_{60}$ fullerene was observed. However, when comparing all possible bisadducts as listed in Table S3 in the Supporting Information, the trans-antipodal bis-adduct, is the least stable adduct. In addition, it also has the highest activation energy of $67.2 \mathrm{~kJ} \mathrm{~mol}^{-1}$ of all bisadducts. Thus, in the absence of a $2^{\text {nd }}$ fullerene, the antipodal bis-adduct would not be thermodynamically favored. This provides strong evidence that a prealignment of $\mathrm{C}_{60}$ :anthracene monomers in the crystal structure and an incomplete dissociation of the anthracene in a synchronous coupled retro DA/DA reaction facilitates the observed topochemically controlled regiospecific anti-podal bisfunctionalization.

\section{The planar intermediate $\mathbf{I N} \boldsymbol{T}_{\text {Mono }}$ with double decker $\pi$ - $\pi$ stacking interactions}

INT $_{\text {Mono }}$ represents an unprecedented case of non-covalent $\pi$ - $\pi$-stacking interactions between a planar and two curved surfaces.

Being exposed to a convex surface, planar structures such as anthracene tend to deform and adapt to the convex shape to maximize attractive dispersive interactions as indicated by the slight bend in the anthracene when forming a noncovalently bound intermediate with $\mathrm{C}_{60}$ as depicted in Figure S17. The deformation of the anthracene can be characterized by the bowl depth - calculated according to Ref. ${ }^{121}$ - amounts to $0.14 \AA$. Such a deformation is also observed for other acenes. ${ }^{106}$ In the presence of a $2^{\text {nd }} \mathrm{C}_{60}$ fullerene as in $\mathbf{I N T}_{\text {Mono }}$ and $\mathbf{I N T}_{\text {Bis }}$ the bowl depth becomes $0.00 \AA$. 
The anthracene is almost perfectly planar with minimal distortion from the gas phase geometry, as also evident from the distortion interaction investigations along the reaction coordinate, where for in $\mathbf{I N T}_{\text {Mono }}$ a minimal distortion of anthracene was found $\left(3.2 \mathrm{~kJ} \mathrm{~mol}^{-1}\right)$. Thus, the alignment with the two fullerenes stabilizes a planar structure and counteract the tendency of a large aromatic hydrocarbons to slightly bend towards $\mathrm{C}_{60}$ surfaces.

Further analyzing the interactions between the $\mathrm{C}_{60}$ :anthracene and the $2^{\text {nd }}$ fullerene $(1, T S(1-$ INT $_{\text {Mono), }}$ INT Mono), we see that the calculated the bowl depth $^{121}$ of anthracene correlates with the stabilization energy: $\mathbf{I N T}_{\text {Mono }}$ (anthracene bowl depth of $0.00 \AA$ ) has the smallest stabilization energy (-51.9 $\left.\mathrm{kJ} \mathrm{mol}^{-1}\right)$, but it gets more favorable for $\mathbf{T S}\left(\mathbf{1}-\mathbf{I N T}_{\mathbf{M o n o}}\right)$, with a bowl depths of anthracene of $0.88 \AA$ and interaction energy of $-57.8 \mathrm{~kJ} \mathrm{~mol}^{-1}$, and it is most pronounced in $\mathbf{1}$, where the interaction stabilizes the complex by $-60.1 \mathrm{~kJ} \mathrm{~mol}^{-1}$, while having a bowl depth of 1.63 $\AA$. This is in line with previous studies, where the bowl depth of hexabenzocorones was found to correlate with $\mathrm{C}_{60}$ interaction strength, reaching an optimum at $1.5 \AA .^{121}$

Concerning the position of the anthracene relative to the two fullerenes, a rotation around the $x$ axis by $32.5^{\circ}$ and a rotation around the $z$-axis by $8^{\circ}$ with respect to. an idealized $\mathrm{C}_{2 v}$ symmetric molecule maximizes favorable dispersive interactions. This is very different from the position of one anthracene (naphthalene or benzene) molecule interacting with a single $\mathrm{C}_{60}$ fullerene. In the case of a single fullerene, the anthracene is aligned directly on top of the bond-to-be-formed, along the common edge formed by two C6 rings on the fullerene. ${ }^{106,122}$ When a second fullerene is added, the simultaneous double decker $\pi-\pi$ stacking interactions induce a rearranging of the anthracene to stack the 6-membered carbon ring of one $\mathrm{C}_{60}$ on its upper ring and of the $2^{\text {nd }} \mathrm{C}_{60}$ fullerene on the lower ring. In contrast, if two benzene molecules are stacked in parallel, the two rings are slightly shifted so that on carbon atom stands over the center of the second benzene molecule. ${ }^{123}$ In addition, the presented intermediate $\mathbf{I N T}_{\text {Mono }}$ shows with $3.06 \AA$ shorter $\pi$ - $\pi$ stacking distances between anthracene and each fullerene (compare also with Ref. ${ }^{124}$ ) as found in planar $\pi-\pi$ stacking structures, for example in benzene dimers the distance between the two faces is $3.8 \AA .{ }^{123}$

\section{CONCLUSION}

The reaction mechanism of the experimentally observed topochemically controlled regiospecific reaction of two $\mathrm{C}_{60}$ :anthracene mono-adducts to form the antipodal $\mathrm{C}_{60}$ :anthracene bis-adduct in complex with $\mathrm{C}_{60}$ was critically analyzed by a quantum chemical investigation. According to this 
study the anthracene transfer proceeds via a synchronous two-step retro Diels-Alder/Diels Alder type process, yielding a low lying intermediate, where a planar anthracene molecule is noncovalently bound to two fullerene moieties. The rate determining step in this reaction is the initial partial cycloreversion to form anthracene sandwiched intermediates, either in the form of $\mathbf{I N T}_{\mathbf{M o n o}}$ or as $\mathbf{I N T}_{\text {Bis. }}$ The presence of the second fullerene not only lowers the activation energies but also stabilizes the intermediates.

Given that in experiment only the formation of $\mathrm{C}_{60}$ and the antipodal bis-adduct occurs, despite the latter being the thermodynamically least stable of all $\mathrm{C}_{60}$ :anthracene bis-adducts, strongly suggests that crystal packing pre-aligns the structures to control the regiospecific reaction. These findings encourage new approaches of topochemically steered $\mathrm{C}_{60}$ multi-functionalization.

The intermediate structures INT $\mathbf{I N o n o}_{\text {and }} \mathbf{I N T}_{\text {Bis }}$ present a central point of interest, as it is to the best of our knowledge a first example of a perfectly planar molecule, trapped between equal and opposing $\pi-\pi$ stacking interactions with 'curved' fullerenes. This does not only shed more light on the nature of $\pi-\pi$ stacking interactions between a planar and (two) curved surfaces, but it is the first example of a double decker type of $\pi-\pi$ stacking in an 'inverted sandwich', which could open up new possibilities in designing functional fullerene based materials.

\section{ASSOCIATED CONTENT}

\section{Supporting Information}

Detailed information about bis-adduct structures and energetics, comparison with crystal structures, details on the distortion-interaction analyzes, detailed Energy Decomposition Analyses, structures of intermediates with smaller acenes, as well as xyz structure coordinates of all investigated species.

\section{AUTHOR INFORMATION}

\section{Corresponding Author}

Maren Podewitz*: maren.podewitz@uibk.ac.at 


\section{Author Contributions}

The manuscript was written through contributions of all authors. All authors have given approval to the final version of the manuscript.

\section{Conflict of Interest}

The authors declare no conflict of interest.

\section{Funding Sources}

FWF (M-2005).

\section{ACKNOWLEDGMENT}

The computational results presented in this work have been achieved using the HPC infrastructure

of the University of Innsbruck (leo3e) and the Vienna Scientific Cluster VSC3. M. P. would like to thank the Austrian Science Fund (FWF) for a generous Lise Meitner Fellowship (M-2005).

\section{REFERENCES}

1. H. W. Kroto, J. R. Heath, S. C. Obrien, R. F. Curl and R. E. Smalley, Nature, 1985, 318, 162-163.

2. H. W. Kroto, Angew. Chem. Int. Ed., 1992, 31, 111-129.

3. W. Krätschmer, L. D. Lamb, K. Fostiropoulos and D. R. Huffman, Nature, 1990, 347, 354-358.

4. F. Wudl, Acc. Chem. Res., 1992, 25, 157-161.

5. F. Diederich and C. Thilgen, Science, 1996, 271, 317-323.

6. J. M. Hawkins, Acc. Chem. Res., 1992, 25, 150-160.

7. H. Schwarz, Angew. Chem. Int. Ed., 1992, 31, 293-298.

8. A. Hirsch and M. Brettreich, Fullerenes, Wiley-VCH, Weinheim, 2005.

9. C. Bingel, Chem. Ber., 1993, 126, 1957-1959.

10. M. Prato and M. Maggini, Acc. Chem. Res., 1998, 31, 519-526.

11. Y. Garcia-Rodeja, M. Sola and I. Fernandez, J. Org. Chem., 2018, 83, 3285-3292.

12. I. Fernandez, M. Sola and F. M. Bickelhaupt, Chem. Eur. J., 2013, 19, 7416-7422.

13. N. Villegas-Escobar, A. Poater, M. Sola, H. F. Schaefer and A. Toro-Labbe, Phys. Chem. Chem. Phys., 2019, 21, 5039-5048. 
14. P. Belik, A. Gügel, J. Spickermann and K. Müllen, Angew. Chem. Int. Ed., 1993, 32, 7880 .

15. F. Diederich, U. Jonas, V. Gramlich, A. Herrmann, H. Ringsdorf and C. Thilgen, Helv. Chim. Acta, 1993, 76, 2445-2453.

16. B. Kräutler and M. Puchberger, Helv. Chim. Acta, 1993, 76, 1626-1631.

17. M. Tsuda, T. Ishida, T. Nogami, S. Kurono and M. Ohashi, J. Chem. Soc., Chem. Commun., 1993, DOI: 10.1039/c39930001296, 1296-1298.

18. R. C. Haddon, J. Am. Chem. Soc., 1997, 119, 1797-1798.

19. J. A. Schlüter, J. M. Seaman, S. Taha, H. Cohen, K. R. Lykke, H. H. Wang and J. M. Williams, J. Chem. Soc. Chem. Commun., 1993, 972-974.

20. A. Duarte-Ruiz, T. Müller, K. Wurst and B. Kräutler, Tetrah., 2001, 57, 3709-3714.

21. A. Duarte-Ruiz, K. Wurst and B. Kräutler, Helv. Chim. Acta, 2001, 84, 2167-2177.

22. B. Kräutler, T. Müller and A. Duarte-Ruiz, Chem. Eur. J., 2001, 7, 3223-3235.

23. F. Cataldo, D. A. Garcia-Hernandez and A. Manchado, Fuller. Nanotub. Car. N., 2015, 23, 760-768.

24. F. Cataldo, D. A. Garcia-Hernandez and A. Manchado, Fuller. Nanotub. Car. N., 2015, 23, 818-823.

25. G. H. Sarova and M. N. Berberan-Santos, Chem. Phys. Lett., 2004, 397, 402-407.

26. W. T. Su, M. Watanabe, Y. J. Chang, P. T. Chou, A. Ghosh and T. J. Chow, Tetrahedron Lett., 2015, 56, 1092-1095.

27. G.-W. Wang, Z.-X. Chen, Y. Murata and K. Komatsu, Tetrahedron, 2005, 61, 48514856.

28. M. Sola, M. Duran and J. Mestres, J. Am. Chem. Soc., 1996, 118, 8920-8924.

29. S. Osuna and K. N. Houk, Chem. Eur J., 2009, 15, 13219-13231.

30. A. Chikama, H. Fueno and H. Fujimoto, J. Phys. Chem., 1995, 99, 8541-8549.

31. A. A. Peyghan and S. Yourdkhani, Struct. Chem., 2014, 25, 785-791.

32. M. Prato, J. Mater. Chem., 1997, 7, 1097-1109.

33. H. Wang, Q. W. Chen and S. Q. Zhou, Chem. Soc. Rev., 2018, 47, 4198-4232.

34. R. Macovez, Front. Mater., 2018, 4, 7.

35. C. C. Wang, Z. X. Guo, S. K. Fu, W. Wu and D. B. Zhu, Prog. Polym. Sci., 2004, 29, 1079-1141. 
36. S. Collavini and J. L. Delgado, Sustain. Energ. Fuels, 2018, 2, 2480-2493.

37. C. J. Brabec, S. Gowrisanker, J. J. M. Halls, D. Laird, S. J. Jia and S. P. Williams, Adv. Mater., 2010, 22, 3839-3856.

38. G. V. Dubacheva, C. K. Liang and D. M. Bassani, Coord. Chem. Rev., 2012, 256, 26282639.

39. M. A. Faist, S. Shoaee, S. Tuladhar, G. F. A. Dibb, S. Foster, W. Gong, T. Kirchartz, D.

D. C. Bradley, J. R. Durrant and J. Nelson, Adv. Energy Mater., 2013, 3, 744-752.

40. A. P. Proudian, M. B. Jaskot, C. Lyiza, D. R. Diercks, B. P. Gorman and J. D. Zimmerman, Nano Lett., 2016, 16, 6086-6091.

41. M. Rudolf, S. V. Kirner and D. M. Guldi, Chem. Soc. Rev., 2016, 45, 612-630.

42. I. Rasovic, Mater. Sci. Technol., 2017, 33, 777-794.

43. R. Bakry, R. M. Vallant, M. Najam-Ul-Haq, M. Rainer, Z. Szabo, C. W. Huck and G. K. Bonn, Int. J. Nanomedicine, 2007, 2, 639-649.

44. J. Lee, S. Mahendra and P. J. J. Alvarez, Acs Nano, 2010, 4, 3580-3590.

45. A. M. Lopez, A. Mateo-Alonso and M. Prato, J. Mater. Chem., 2011, 21, 1305-1318.

46. D. Jariwala, V. K. Sangwan, L. J. Lauhon, T. J. Marks and M. C. Hersam, Chem. Soc. Rev., 2013, 42, 2824-2860.

47. L. K. Shrestha, Q. M. Ji, T. Mori, K. Miyazawa, Y. Yamauchi, J. P. Hill and K. Ariga, Chem. Asian J., 2013, 8, 1662-1679.

48. V. Biju, Chem. Soc. Rev., 2014, 43, 744-764.

49. W. B. Yan, S. M. Seifermann, P. Pierrat and S. Brase, Org. Biomol. Chem., 2015, 13, 2554.

50. J. Kotteritzsch, R. Geitner, J. Ahner, M. Abend, S. Zechel, J. Vitz, S. Hoeppener, B. Dietzek, M. Schmitt, J. Popp, U. S. Schubert and M. D. Hager, J. Appl. Polym. Sci., 2018, $135,14$.

51. R. Geitner, J. Kotteritzsch, M. Siegmann, R. Fritzsch, T. W. Bocklitz, M. D. Hager, U. S. Schubert, S. Grafe, B. Dietzek, M. Schmitt and J. Popp, Phys. Chem. Chem. Phys., 2016, 18, 17973-17982.

52. A. Hirsch, I. Lamparth and H. R. Karfunkel, Angew. Chem. Int. Ed., 1994, 33, 437-438.

53. F. Djojo, A. Herzog, I. Lamparth, F. Hampel and A. Hirsch, Chem. Eur. J., 1996, 2, $1537-1547$. 
54. J. F. Nierengarten, V. Gramlich, F. Cardullo and F. Diederich, Angew. Chem. Int. Ed., 1996, 35, 2101-2103.

55. A. Kraszewska, P. Rivera-Fuentes, G. Rapenne, J. Crassous, A. G. Petrovic, J. L. AlonsoGomez, E. Huerta, F. Diederich and C. Thilgen, Eur. J. Org. Chem., 2010, 4402-4411.

56. W. Y. Qian and Y. Rubin, Angew. Chem. Int. Ed., 1999, 38, 2356-2360.

57. W. Qian and Y. Rubin, J. Am. Chem. Soc., 2000, 122, 9564-9565.

58. R. Schwenninger, T. Müller and B. Kräutler, J. Am. Chem. Soc., 1997, 119, 9317-9318.

59. I. Lamparth, C. Maichle-Mössmer and A. Hirsch, Angew. Chem. Int. Ed., 1995, 34, 16071609.

60. A. Hirsch, I. Lamparth, T. Grösser and H. R. Karfunkel, J. Am. Chem. Soc., 1994, 116, 9385-9386.

61. F. Cardullo, L. Isaacs, F. Diederich, J. P. Gisselbrecht, C. Boudon and M. Gross, Chem. Commun., 1996, 797-799.

62. G. Schick, M. Levitus, L. Kvetko, B. A. Johnson, I. Lamparth, R. Lunkwitz, B. Ma, S. I. Khan, M. A. Garcia-Garibay and Y. Rubin, J. Am. Chem. Soc., 1999, 121, 3246-3247.

63. B. Kräutler and J. Maynollo, Angew. Chem. Int. Ed., 1995, 34, 87-88.

64. A. Duarte-Ruiz, K. Wurst and B. Kräutler, Helv. Chim. Acta, 2008, 91, 1401-1408.

65. F. Cataldo, D. A. Garcia-Hernandez and A. Manchado, Fuller. Nanotub. Car. N., 2014, 22, $565-574$.

66. B. Kräutler, T. Müller, J. Maynollo, K. Gruber, C. Kratky, P. Ochsenbein, D. Schwarzenbach and H. B. Bürgi, Angew. Chem. Int. Ed., 1996, 35, 1204-1206.

67. A. Duarte-Ruiz, K. Wurst and B. Kräutler, Helv. Chim. Acta, 2001, 84, 2167-2177.

68. A. Duarte-Ruiz, T. Müller, K. Wurst and B. Kräutler, Tetrahedron, 2001, 57, 3709-3714.

69. W. Jia and G. P. Miller, Fuller. Nanotub. Car. N., 2008, 16, 58-65.

70. A. Duarte-Ruiz, L. Echegoyen, A. Aya and F. Gomez-Baquero, J. Mex. Chem. Soc., 2009, 53, 169-173.

71. D. S. Sabirov, A. O. Terentyev and F. Cataldo, Comput. Theor. Chem., 2016, 1081, 4448.

72. I. Fleming, in Molecular Orbitals and Organic Chemical Reactions, John Wiley \& Sons Chichester, UK, 2010, DOI: 10.1002/9780470689493.ch6, pp. 253-368. 
73. A. H. Streitwieser, Clayton H.; Kosower and E. M., Introduction to organic chemistry, Macmillan, New York, 1992.

74. T. H. Lowry and K. S. Richardson, Mechanism and theory in organic chemistry, Harper \& Row, New York, 1976.

75. R. B. Woodward and R. Hoffmann, Angew. Chem. Int. Ed., 1969, 8, 781.

76. J. Sauer and R. Sustmann, Angew. Chem. Int. Ed., 1980, 19, 779-807.

77. M. B. Smith and J. March, March's Advanced Organic Chemistry, Wiley-Interscience, Hoboken New Jersey, 6th edn., 2007.

78. K. N. Houk, J. Am. Chem. Soc., 1973, 95, 4092-4094.

79. K. N. Houk, Y. Li and J. D. Evanseck, Angew. Chem. Int. Ed., 1992, 31, 682-708.

80. S. Osuna, M. Swart and M. Sola, Phys. Chem. Chem. Phys., 2011, 13, 3585-3603.

81. I. Lamparth, C. Maichlemossmer and A. Hirsch, Angew. Chem. Int. Ed., 1995, 34, 16071609.

82. G. W. Wang, M. Saunders and R. J. Cross, J. Am. Chem. Soc., 2001, 123, 256-259.

83. G. W. Wang, Z. X. Chen, Y. Murata and K. Komatsu, Tetrahedron, 2005, 61, 4851-4856.

84. M. A. Herranz, N. Martin, J. Ramey and D. M. Guldi, Chem. Commun., 2002, DOI: 10.1039/b207361g, 2968-2969.

85. Y. Takaguchi, T. Tajima, K. Ohta, J. Motoyoshiya, H. Aoyama, T. Wakahara, T. Akasaka, M. Fujitsuka and O. Ito, Angew. Chem. Int. Ed., 2002, 41, 817-+.

86. K. N. Houk, Y. T. Lin and F. K. Brown, J. Am. Chem. Soc., 1986, 108, 554-556.

87. H. J. Jiao and P. V. Schleyer, J. Phys. Org. Chem., 1998, 11, 655-662.

88. E. Goldstein, B. Beno and K. N. Houk, J. Am. Chem. Soc., 1996, 118, 6036-6043.

89. K. N. Houk, J. Gonzalez and Y. Li, Acc. Chem. Res., 1995, 28, 81-90.

90. Y. Li and K. N. Houk, J. Am. Chem. Soc., 1993, 115, 7478-7485.

91. K. N. Houk, Acc. Chem. Res., 1975, 8, 361-369.

92. R. C. Haddon, Science, 1993, 261, 1545-1550.

93. F. M. Bickelhaupt and K. N. Houk, Angew. Chem. Int. Ed., 2017, 56, 10070-10086.

94. B. Willocq, V. Lemaur, M. El Garah, A. Ciesielski, P. Samori, J. M. Raquez, P. Dubois and J. Cornil, Chem. Commun., 2016, 52, 7608-7611.

95. F. Diederich and R. Kessinger, Acc. Chem. Res., 1999, 32, 537-545.

96. Y. Nakamura, K. O-kawa and J. Nishimura, Bull. Chem. Soc. Jpn., 2003, 76, 865-882. 
97. L. Chaker, A. B. Yongye, A. Nefzi and K. Martinez-Mayorga, J. Phys. Org. Chem., 2012, 25, 894-901.

98. M. Garcia-Borras, S. Osuna, M. Swart, J. M. Luis and M. Sola, Chem. Commun., 2013, 49, 1220-1222.

99. T. K. Roy Dennington, and John Millam, GaussView 4.1.2, Semichem Inc.: Shawnee Mission, KS, 2009

100. TURBOMOLE V7.3 2018, a development of University of Karlsruhe and Forschungszentrum Karlsruhe GmbH, 1989-2007, TURBOMOLE GmbH, since 2007; available from http://www.turbomole.com.

101. J. C. Slater, Phys. Rev., 1951, 81, 385-390.

102. S. H. Vosko, L. Wilk and M. Nusair, Can. J. Phys., 1980, 58, 1200-1211.

103. J. P. Perdew, Phys. Rev. B, 1986, 33, 8822-8824.

104. A. D. Becke, Phys. Rev. A, 1988, 38, 3098-3100.

105. A. Schäfer, H. Horn and R. Ahlrichs, J. Chem. Phys., 1992, 97, 2571-2577.

106. S. Osuna, M. Swart and M. Sola, J. Phys. Chem. A, 2011, 115, 3491-3496.

107. S. Grimme, J. Antony, S. Ehrlich and H. Krieg, J. Chem. Phys., 2010, 132, 154104.

108. A. Schäfer, C. Huber and R. Ahlrichs, J. Chem. Phys., 1994, 100, 5829-5835.

109. F. Weigend and R. Ahlrichs, Phys. Chem. Chem. Phys., 2005, 7, 3297-3305.

110. C. T. Lee, W. T. Yang and R. G. Parr, Phys. Rev. B, 1988, 37, 785-789.

111. A. D. Becke, J. Chem. Phys., 1993, 98, 5648-5652.

112. A. P. Scott and L. Radom, J. Phys. Chem., 1996, 100, 16502-16513.

113. Schrodinger, LLC, unpublished work.

114. N. OriginLab Corporation, MA, USA., OriginPro).

115. J. Contreras-Garcia, E. R. Johnson, S. Keinan, R. Chaudret, J. P. Piquemal, D. N. Beratan and W. T. Yang, J. Chem. Theory Comput., 2011, 7, 625-632.

116. E. R. Johnson, S. Keinan, P. Mori-Sanchez, J. Contreras-Garcia, A. J. Cohen and W. T. Yang, J. Am. Chem. Soc., 2010, 132, 6498-6506.

117. W. Humphrey, A. Dalke and K. Schulten, J. Mol. Graph. Model., 1996, 14, 33-38.

118. L. P. Wolters and F. M. Bickelhaupt, Wiley Interdiscip. Rev. Comput. Mol., 2015, 5, 324343.

119. D. H. Ess and K. N. Houk, J. Am. Chem. Soc., 2007, 129, 10646-+. 
120. B. Kräutler, T. Müller, J. Maynollo, K. Gruber, C. Kratky, P. Ochsenbein, D. Schwarzenbach and H. B. Burgi, Angew. Chem. Int. Ed., 1996, 35, 1204-1206.

121. D. Sepulveda, Y. F. Guan, U. Rangel and S. E. Wheeler, Org. Biomol. Chem., 2017, 15, 6042-6049.

122. M. M. Li, Y. B. Wang, Y. Zhang and W. Wang, J. Phys. Chem. A, 2016, 120, 5766-5772.

123. R. G. Huber, M. A. Margreiter, J. E. Fuchs, S. von Grafenstein, C. S. Tautermann, K. R. Liedl and T. Fox, J. Chem. Inf. Model., 2014, 54, 1371-1379.

124. J. W. Li, Y. Y. Liu, Y. Qian, L. Li, L. H. Xie, J. Z. Shang, T. Yu, M. D. Yi and W. Huang, Phys. Chem. Chem. Phys., 2013, 15, 12694-12701. 